\title{
Editorial
}

\section{Reviewer recognition and new plans for 2016}

DOI 10.1515/aot-2016-0007

The year 2015 was a great year for Optics and for Advanced Optical Technologies as well. The optics community celebrated the International Year of Light with thousands of events around the world. People enjoyed the beauty of light in all its facets and shared it with children, students, and many other people. The homepage of the global initiative www.light2015.org is still worth a visit.

A special highlight for Advanced Optical Technologies in 2015 was probably reached when the Scopus Content Selection and Advisory Board completed its review of the journal and advised that the title will be accepted for inclusion in Scopus. This has been done now, and the visibility of all AOT articles is essentially improved. The application for Web of Science is still running, and hopefully, their review will conclude in 2016.

The journal itself developed further in 2015. We published a number on topical issues on highly interesting topics:

- Micro-optics for industrial applications,

- Integrated photonic devices: sensors, materials, systems,
- Optical lithography,

- Standards in optics and optical measurement.

Many excellent scientific papers were included. In addition, a number of non-academic articles (VIEWS) were published, the most remarkable might have been "ITRS lithography roadmap: 2015 challenges" by Mark Neisser and Stefan Wurm, a review of the options for lithography with or without EUV. Another milestone was the VIEWS article on "Lenses for film and television: an international survey" by Peter C. Slansky and Katrin Richthofer. That was a fascinating glance into the world of movie maker optics.

Again, it should be mentioned that this journal depends on the great voluntary work of the authors and the reviewers. While the first can be judged upon by their articles, the latter work in the background. Nevertheless, peer review is a corner stone of the scientific process. Most articles get improved in a revision after the reviewers gave some helpful and inspiring feedback.

In 2014, we started the recognition of our peer reviewers with a public acknowledgment, and I am happy to make this a tradition. In the following, you may find all reviewer names:

\section{5 reviewers in advanced optical technologies}

\author{
Ilya Alexeev \\ Shigehisa Arai \\ David Attwood \\ Liam Barry \\ Peter Blattner \\ Florian Bociort \\ Azzedine Boudrioua \\ Peter O’Brien \\ Olaf Brox \\ William Cassarly \\ Pavel Cheben \\ Ya Cheng \\ Francis Clube \\ Giampiero Contestabile \\ Aleksandra Cvetkovic
}

www.degruyter.com/aot

(C) 2016 THOSS Media and De Gruyter

\author{
Christopher T. DeRose \\ Henrik Ehlers \\ Akira Endo \\ Carsten Gachot \\ David Gillen \\ Norbert Grote \\ Martijn Heck \\ Alois Herkommer \\ Rafael Jordan \\ Larissa Juschkin \\ Norbert Kaiser \\ Pentti Karioja \\ Peter G. Kazansky \\ Sven Kiontke \\ Jongwook Kye \\ Roland Lachmayer \\ Paul Leiderer
}




Xaveer Leijtens
Daan Lenstra
Yongfeng Lu
Chris Mack
Andrea Melloni
Antonin Miks
Martin Mügge
Juliana Müller
Seiji Nagahara
Josep Nicolas
Nobuhiko Nishiyama
Christopher Ober
Andreas Ostendorf
Robert Palmer
Adam Phenis
Marco Pisani
Detlev Ristau
Chris Roeloffzen
Bob Rollinger
Masaaki Sakakura
Oliver Sandfuchs
Thomas Scherübl
Bernhard Schmitz
Jonathan D. Shephard
Tadahiko Shinshi
Jan Siegel
Mikael Sjödahl
David H. Sliney

\section{New plans for 2016}

First we are pleased to welcome several new board members officially, who joined us last year:

- Andreas Erdmann - Fraunhofer IISB, Germany

- Yanqiu Li - Beijing Institute of Technology, China

- Guohai Situ - Shanghai Institute of Optics and Fine Mechanics, China

We are looking forward to working with them on the further improvement of the journal! Then, we would like to turn your attention to the topics AOT will focus on in 2016. A list of topics has been fixed, and all authors are welcome to submit related papers for the following topics:

- Optics for Material Processing

Guest editors: Koji Sugioka (RIKEN, Japan), Stefan Kaierle (Laserzentrum Hannover, Germany)

- Optics for illumination

Guest editors: Cornelius Neumann, Ulrich Lemmer (KIT, Karlsruhe, Germany)
Razvan Stoian

John C. Stover

John Sturtevant

Robert Tamburo

Amalia Torre

Michael Totzeck

Katy Voisey

Hui-Tian Wang

Jeremy Witzens

Stefan Wurm

Allen Yi

William A. Zortman

Let us have a short look on the journal statistics: The average processing time for a paper from submission to decision in AOT decreased from 49 in 2014 to 41 days in 2015. The average time reviewers needed for their work was 15 days, up from 13 days in 2014. You should assume at least one revision for most papers. That is very fast and a great help for all the authors.

We would like to express our cordial gratitude to all the reviewers, as there would be no journal without this voluntary service. The work of the reviewers and the feedback from the community is a constant impetus for the editorial team to keep thinking how we can improve the service and, finally, how we can make this journal an even more valuable resource for the optics community.

\section{- Aspherical Optics}

Guest editors: Sven Kiontke (asphericon, Jena, Germany), Santiago Royo (Universitat Politècnica de Catalunya, Obstech SpA, Spain)

\section{- Polymeroptics}

Guest editors: Stefan Bäumer (TNO Delft, The Netherlands), Allen Yi (Ohio State University, Columbus, USA).

- Optical 3D sensor systems

Guest editors: Gunther Notni (Fraunhofer IOF Jena, TU Ilmenau, Germany), N.N.

It should be mentioned that these topics will be treated as the main content for the respective issues, but as you may already see in this issue, this is by no means a limitation. Besides the focus topics, AOT intends to publish papers from all fields of applied optics in a separate section in each issue. Furthermore, we have developed the format of VIEWS papers, where people from the academic community as well as from industry can publish essential 
information that might not directly match the criteria of scientific publications. Those are market reviews, interviews, or even individual views on the development of topics relevant to the optics community.

After all, it is a challenge and a great pleasure to develop this publication platform with the optics community in industry and academia. For further improvements, we appreciate all kinds of feedback. Please do not hesitate to contact us. You may contact us via email, our website www.degruyter.com/aot, or through various social media.
We are looking forward to hearing from you.

Yours sincerely,

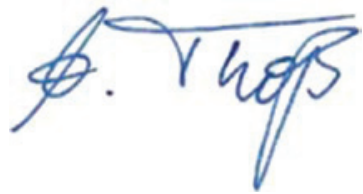

Andreas Thoss

Publisher

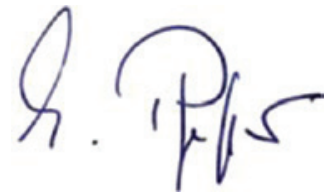

Michael Pfeffer

Editor-in-Chief

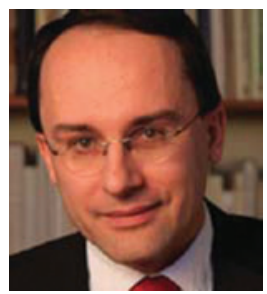

Andreas Thoss studied physics and received his diploma and PhD degrees from the Free University Berlin in 1995 and 2003, respectively. For both degrees, he did research at the Max-Born-Institute Berlin on the field of ultrashort and ultra-intense laser pulses. From 1996 to 1999, he worked as a development engineer for medical laser systems with Aesculap-Meditec (now ZEISS Meditec) in Jena. In 2003, he joined the international publishing house, John Wiley \& Sons. There, he gathered comprehensive experience as Publisher, Editor, and Commissioning Editor in the areas of book, journal, and online publishing. Among others, he cofounded the journals, Laser \& Photonics Reviews (2007) and the Journal of Biophotonics (2008). Since its foundation in 2010, he manages THOSS Media, where he cofounded Advanced Optical Technologies.

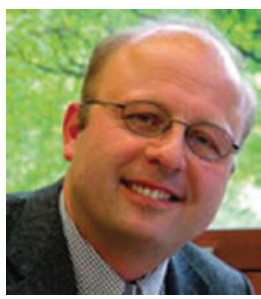

Michael Pfeffer graduated in 1998 at the Institute of Applied Optics at EPFL (Switzerland), obtaining his PhD for a thesis in the field of optical nanotechnology. In 2002, after several years of working in the Swiss optics industry, he was appointed Full Professor of Optics and Engineering in the Department of Physical Engineering of Hochschule Ravensburg-Weingarten, University of Applied Sciences (Germany). Dr. Pfeffer teaches and researches in the field of optics, physical instrument design, and nanotechnology. Currently, he serves as Vice-Rector for Research and International Relations. In 2005, the General Membership Meeting elected him to the Executive Board and CEO for the DGaO-Annual Meeting 2006. From 2008 to 2012 he served as President of the German Society of applied Optics (DGaO). In 2012 he was elected as Secretary of the Board of the European Optical Society (EOS). Dr. Pfeffer is member of the German Physical Society (DPG), the German Society of Engineers (VDI), and the Standards Committee Precision Engineering and Optics of the German Institute of Standardization (DIN). 